\title{
Effects of nicotine on choroidal thickness by enhanced depth imaging optical coherence tomography
}

\section{Efectos de la nicotina en el grosor coroideo mediante tomografía de coherencia óptica con imagen de profundidad mejorada}

\author{
Yolanda Villalpando-Gómez ${ }^{1 *}$, Itzel Espinosa-Soto ${ }^{1}$, Juan A. Ramírez-Estudillo ${ }^{1}$ and \\ Atzin Robles-Contreras ${ }^{2}$ \\ ${ }^{1}$ Departament of Retina and Vitreous; ${ }^{2}$ Centro de Investigación Biomédica. Hospital Nuestra Señora de la Luz, Mexico City, Mexico
}

\begin{abstract}
Background: Smoking and nicotine are well-known risk factors for cardiovascular diseases, so it is expected that they are associated with vascular changes in the organism, including the choroidal vasculature. Purpose: To evaluate the effects of nicotine on choroidal thickness in healthy patients by enhanced depth imaging optical coherence tomography (EDI-OCT). Methods: Case-control study that measured choroidal thickness in healthy subjects after chewing a 4 mg nicotine gum compared to a control group that received nicotine-free chewing gum. For descriptive statistics frequencies, means and standard deviation were used. For inferential statistics, one-way analysis of variance was used for intergroup comparisons. Results: Sixty-four eyes were included. When comparing choroidal thickness in the control group at baseline, 1 hour and 2 hours, no significant difference was observed ( $p=0.29, p=0.13$, respectively). Additionally, when we performed the comparison of the group with nicotine, we did not observe a statistical significance between baseline, 1-hour and 2-hour choroidal thickness ( $p=0.57, p=1.43$, respectively). Conclusion: In our study, we did not observe that nicotine chewing gum induced transient changes in choroidal thickness; these changes could be related to chronic nicotine use and the subsequent damage generated by it.
\end{abstract}

Key words: Choroidal thickness. Nicotine. Optical coherence tomography.

\section{Resumen}

Introducción: El tabaquismo y la nicotina son factores de riesgo conocidos para diversas enfermedades cardiovasculares, por lo que es de esperar que estos se asocien a cambios vasculares en diversas partes del organismo, incluyendo la vasculatura coroidea. Objetivo: Evaluar los efectos que tiene la nicotina en el grosor coroideo en pacientes sanos medido mediante la tomografía de coherencia óptica con imagen de profundidad mejorada (EDI-OCT). Material y métodos: Estudio de casos y controles, en el cual se midió el grosor coroideo a sujetos sanos tras consumir una goma de mascar con $4 \mathrm{mg}$ de nicotina y se comparó con un grupo control al cual se le administró una goma de mascar sin nicotina. Para la estadística descriptiva se utilizaron frecuencias, medias y desviación estándar. Para la estadística inferencial se realizó un análisis

Correspondence:

*Yolanda Villalpando-Gómez

Ezequiel Montes 135

Col. Tabacalera, Del. Cuauhtémoc

Date of reception: 23-02-2017

Date of acceptance: 21-06-2017

DOI: 10.24875/RMOE.M18000013
Available online: 14-05-2018 Rev Mex Oftalmol(Eng).2018;92(3):102-107 www.rmo.com.mx the CC BY-NC-ND 
de varianza de un factor para la comparación intergrupo. Resultados: Se incluyeron 64 ojos. En la comparación del grosor coroideo en el grupo control en el momento baseline, a la hora y a las dos horas, no se observó una diferencia significativa $(p=0.29$ y $p=0.13$, respectivamente). Por otra parte, al realizar la comparación del grupo con nicotina, no observamos una diferencia estadísticamente significativa entre el grosor coroideo baseline, a la hora y las dos horas $(p=0.57$ y $p=1.43$, respectivamente). Conclusión: En nuestro estudio no observamos que la goma de mascar con nicotina generara cambios transitorios en el grosor coroideo. Estos cambios podrían estar relacionados con el consumo crónico de nicotina y con el daño consiguiente generado por este consumo.

Palabras clave: Grosor coroideo. Nicotina. Tomografía de coherencia óptica.

\section{Introduction}

The choroid is the vascular structure with greater blood flow within the body. It is a complex structure, responsible for supplying oxygen to the external layers of the retina, and its study has been of great interest over the years ${ }^{1}$.

Optical coherence tomography (OCT) is a noninvasive study that is used to visualize the morphology of the layers of the retina; however, choroidal anatomy is poorly visualized due to the low penetration of the signal through the retinal pigment epithelium ${ }^{2,3}$.

Enhanced depth image OCT (EDI-OCT) represents an image capturing modality based on a software that uses the characteristics of the spectral-domain OCT (SD-OCT), such as the number of scans (more than $100)$ and eye tracking. Its use decreases the distance between the device and the eye, obtaining an inverted image that allows a better visualization of the choroid and the chorio-scleral interface ${ }^{4}$.

Measuring the choroidal thickness by EDI-OCT has shown that this structure plays a very important role in the pathophysiology of diseases such as central serous chorioretinopathy ${ }^{5}$, polypoidal choroidal vasculopathy ${ }^{6,7}$, Vogt-Koyanagi-Harada syndrome $e^{8-10}$ or age-related macular degeneration ${ }^{11-14}$.

Chronic smoking is considered a risk factor for various ocular vascular diseases whose pathophysiology is not completely understood; however, it has been observed that it results in an increase in choroidal vascular resistance ${ }^{15,16}$.

In smokers, a decrease in choroidal thickness that persists up to three hours after smoking has been reported $^{17}$. This decrease has also been reported in healthy smokers; however, it has been observed that this effect is transient and returns to normal one hour after smoking a cigarette. No statistically significant difference has been found in the baseline OCT compared to controls ${ }^{18}$.

In a study conducted in 26 people, Sanchez, et al. observed a statistically significant decrease in subfoveal choroidal thickness in smokers compared to nonsmokers, which is related to the decrease in choroidal flow caused by vasoconstriction secondary to the nicotine contained in cigarettes ${ }^{19}$.

In our study, we analyzed the changes in choroidal thickness caused by nicotine alone, and not by all the chemical components of a cigarette. On the other hand, there are few reports of changes in choroidal thickness secondary to nicotine consumption in the Mexican population.

\section{Material and Methods}

This is a case-control study that included healthy people who decided to participate, signed a written informed consent form and were over 18 years of age; from any gender and without concurrent ophthalmological or systemic pathologies (smokers were not excluded). Female pregnant patients were excluded. We had a control group that received a chewing gum without nicotine and an experimental group that chewed a $4 \mathrm{mg}$ nicotine gum. This work was approved by the local ethics in research committee according to the risk of the General Health Law and the Declaration of Helsinki.

An EDI-OCT was taken under dilation between 9 and 11 o'clock in the morning for the baseline measurement in both groups; afterwards, each individual received a $4 \mathrm{mg}$ nicotine gum or a common caramel gum. They were randomly assigned to the experimental group or the control group. The patient and the principabinvestigator were blinded to the group assignment. It was requested that the gums were chewed for at least 10 minutes, and the test was repeated one and two hours later. The measurement in microns was performed at the subfoveal level from the outer side of the hyperreflectic line corresponding to the pigment epithelium/Bruch membrane complex to the inner side of the hyperreflectic line corresponding to the choroid-sclera interface (choroidal vascular thickness according to the classification of Yiu, et al.). 
To obtain the images, the Heidelberg spectral-domain OCT was used with enhanced depth imaging, evaluated by a single observer.

The variables considered for the analysis were patient's age, baseline choroidal thickness compared to one-hour, two-hour and three-hour choroidal thickness.

For statistical analysis, the GraphPad Prism program (version 5.00) was used and descriptive statistics were performed with averages, frequencies, standard deviation, mean and ranges. For inferential statistics, differences were established between groups using the t-Student test and intergroup differences, performing a one-way analysis of variance.

\section{Ethical considerations}

This is an interventional study that analyzed the images obtained by a non-invasive procedure. The subjects in the experimental group received a $4 \mathrm{mg}$ nicotine gum, which has been used in similar studies. The levels of nicotine achieved with the chewing gum are lower than those with a cigarette, besides, the risk of addiction is zero. This work was approved by the local ethics in research committee according to the risk of the General Health Law and the Declaration of HeIsinki. All participants signed a written informed consent form.

\section{Study risks for participants}

The described risks associated with nicotine gum use are mild side effects, such as burning of the throat, headache or nausea. The use of these gums is not recommended in pregnant or lactating women, although some women have used them because they have a less harmful effect than cigarettes; however, for greater safety in the protocol, this group of subjects were excluded from the study.

\section{Results}

We included 64 eyes of 32 patients, observing within the general characteristics that the mean age was 28 \pm 2 years, male patients predominated in $65.6 \%$ and all of them were students (Table 1).

Regarding non-pathological personal history, 31\% of the patients were smokers. There was no relevant pathological history in any participant (Table 1).

Of the total of patients, $53.1 \%$ corresponded to the control group (chewing gum without nicotine) and $46.8 \%$ to the experimental group (chewing gum with nicotine).
Table 1. General characteristics

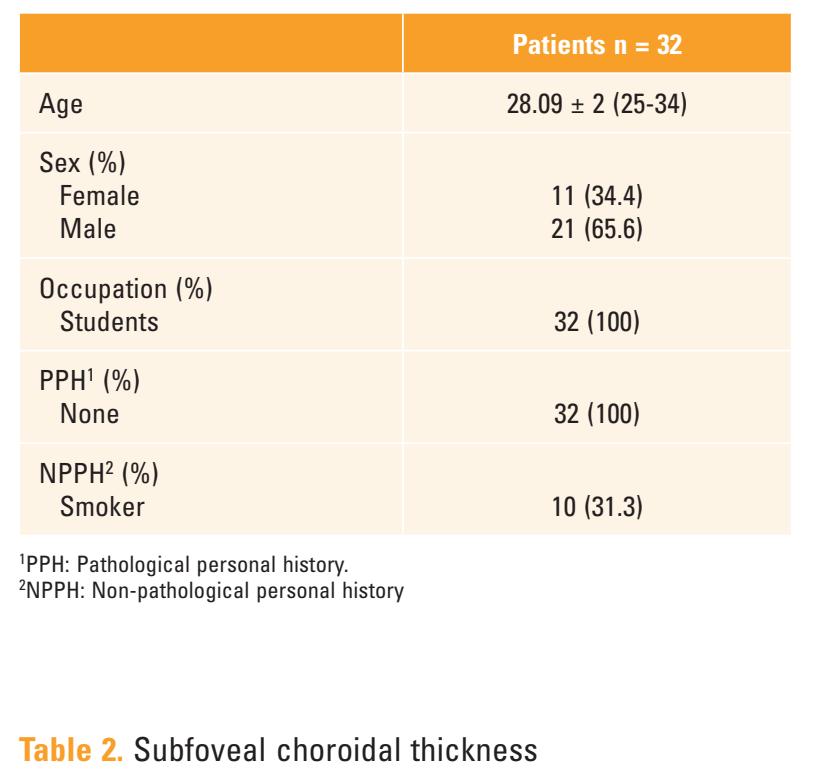

\begin{tabular}{|l|l|l|}
\hline & Without nicotine & With nicotine \\
\hline Baseline* & $324.1 \pm 72.25$ & $355.0 \pm 94.85$ \\
\hline 1 hour* & $323.7 \pm 71.45$ & $355.2 \pm 96.34$ \\
\hline 2 hours* & $323.0 \pm 72.93$ & $352.8 \pm 94.70$ \\
\hline
\end{tabular}

The observed mean of baseline subfoveal choroidal thickness in the control group was $324.1 \mu \mathrm{m}, 323.7 \mu \mathrm{m}$ at one hour and $323.0 \mu \mathrm{m}$ at two hours; in the experimental group, the baseline measure was $355.0 \mu \mathrm{m}, 355.2 \mu \mathrm{m}$ at one hour and $352.8 \mu \mathrm{m}$ at two hours (Table 2).

When performing the comparison between groups, in the control group no statistically significant difference was observed between the baseline subfoveal choroidal thickness compared to, one-hour and two-hour measurements ( $p=0.29$ and $p=0.13$, respectively). On the other hand, when performing the correlation in the experimental group between the baseline choroidal thickness compared to the first and second hours, there was also no statistically significant difference $(p=0.57$ and $p=1.43$, respectively) (Fig. 1).

Several comparisons were made to observe if there was any difference: baseline nicotine vs. baseline without nicotine, with nicotine at one hour vs. without nicotine at one hour and with nicotine at two hours versus without nicotine at two hours; however, as in the previous correlations, this was not significant $(p=0.13$, $p=0.10$ and $p=0.14$, respectively).

Finally, a comparison between smokers and nonsmokers was made between the baseline, one-hour and 


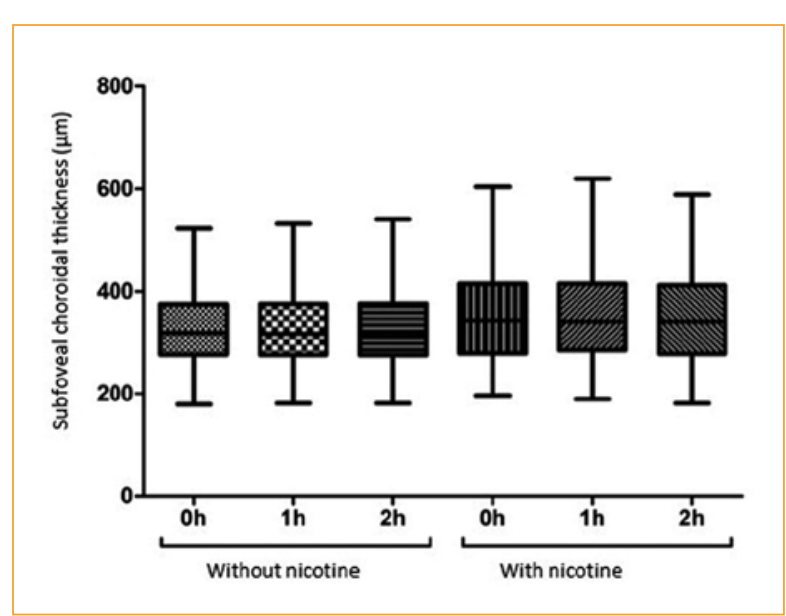

Figure 1. Choroidal thickness comparison between groups.

two-hour measurements, and no statistically significant difference in subfoveal choroidal thickness was observed (Fig. 2).

\section{Discussion}

When performing the analysis of our results we observed that there was no statistically significant difference in baseline choroidal thickness between the control group and the experimental group. Similarly, when performing an intergroup comparison of baseline vs. one hour, baseline vs. two hours, as well as one hour vs. two hours, no significant difference was found in both groups. On the other hand, when performing the comparison between groups at one hour in the group with nicotine vs. the group without nicotine, as well as at two hours between both groups, baseline vs. one hour, baseline vs. two hours and one hour vs. two hours, no statistically significant difference was observed.

Sizmaz, et al. conducted a study in smokers (study group) and nonsmokers (control group), where the participants of the study group smoked a cigarette. The authors measured the choroidal thickness in both groups at baseline, at one hour and at three hours, reporting, unlike our study, a statistically significant decrease in choroidal thickness at one hour and at three hours compared to the baseline measurement in the study group ${ }^{17}$. This difference could be explained by the higher plasma concentration of nicotine reached when smoking a cigarette vs. oral intake.

On the other hand, Ulas, et al. evaluated the effects produced by smoking on subfoveal choroidal thickness, and observed an increase in choroidal thickness in the first 5 minutes after smoking a cigarette, and a return to baseline choroidal thickness at one hour. This change suggests a much more dynamic behavior of the choroid than we believed, so it would be very useful to make earlier measurements ${ }^{18}$.

Moschos, et al. conducted a study published in 2016 that included patients with a 25-year history of smoking around one pack a day for at least 1 year; compared to controls, they reported a significant decrease in choroidal thickness. This difference observed with our study could be related, as they mention in their conclusions, to the changes caused by chronic smoking, since it is related to endothelial dysfunction and choroidal reactivity induced by smoking 20 .

Similar to our study, Tayyab, et al. observed in a group of 80 smoking and non-smoking patients, that there was no statistically significant difference in choroidal thickness between both groups ${ }^{21}$.

Benowitz, et al. report that nicotine gum contains half the amount of nicotine contained in a cigarette, and that the highest level of nicotine in blood is achieved after 30 minutes. This increase is gradual, persistent, and decreases slowly for two hours, which is why, in our study, we administered the second dose at that time point, when plasma nicotine levels were still maintained, and the last one, at three hours, the time point at which those levels decrease ${ }^{22}$.

In contrast to our study, Zengin, et al. conducted a study in 32 patients, investigating the effect of nicotine on choroidal thickness using a $4 \mathrm{mg}$ nicotine gum, and reporting a thinning of choroidal thickness. This difference with our study could be related to the nicotine chewing gum being administered longer, since in our study it was chewed for 10 minutes and in the aforementioned study for one hour, probably explaining the existence of nicotine retention in the chewing gum $^{23}$.

Our results show us that nicotine chewing gum had no transient effects on subfoveal choroidal thickness. We did not find differences in choroidal thickness between the nicotine chewing gum group and the control group despite the measurement at one hour and at two hours, time points in which high levels of nicotine are found in blood that are maintained and then decrease after two hours of administration.

On the other hand, we could say that the changes described in the vasculature regarding endothelial damage and increased vascular resistance, could be related to chronic damage secondary to exposure time 


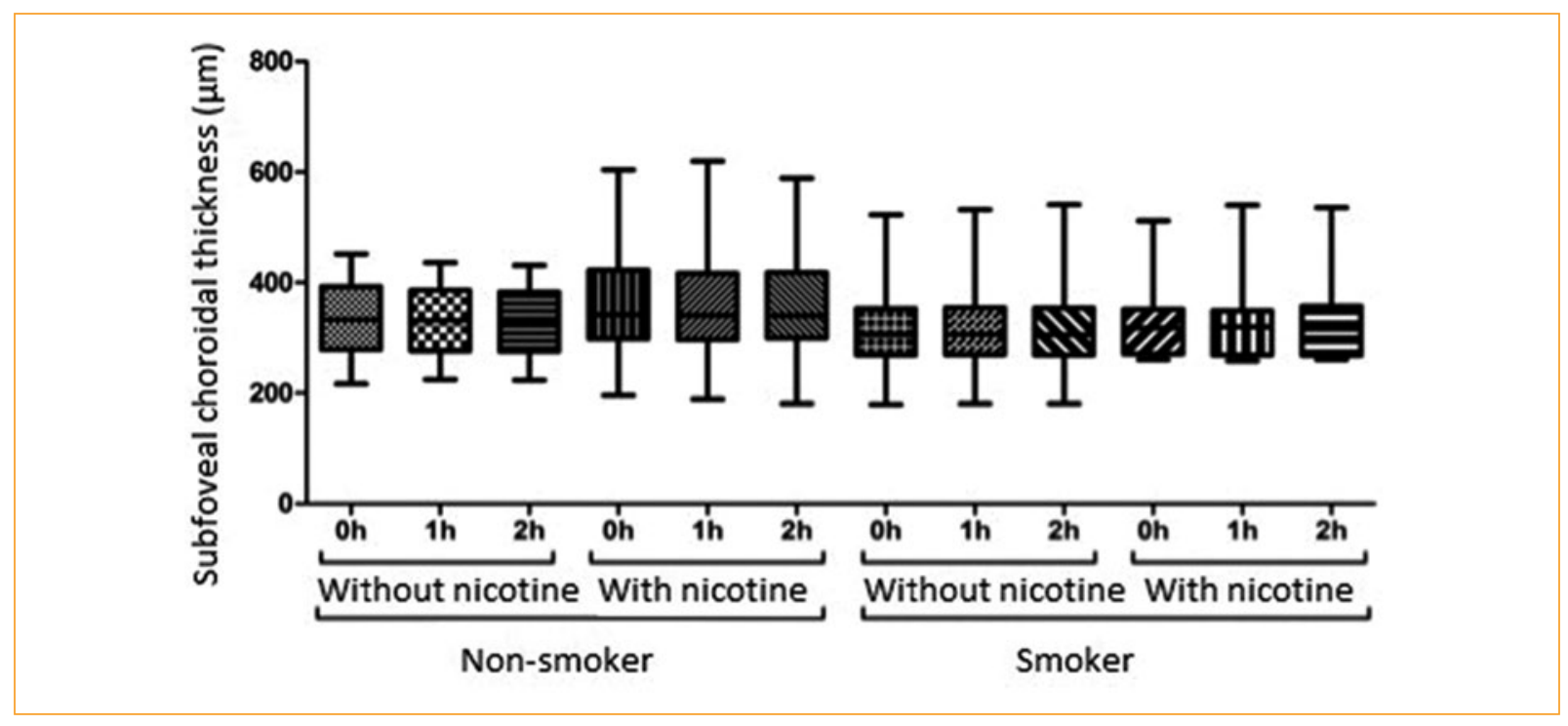

Figure 2. Choroidal thickness comparison between smokers and non-smokers.

and the number of cigarettes smoked per day (smoking rate).

Therefore, we conclude that in our study no transient changes were observed in choroidal thickness with the $4 \mathrm{mg}$ nicotine chewing gum and that the changes reported in the choroidal vasculature associated with nicotine could be related to the chronic consumption of nicotine. In future studies, it would be very useful to measure nicotine plasmatic levels to know the degree of absorption and the maximum peak of nicotine, and thus, make a more specific correlation.

Our study has some limitations, such as the small number of patients, the subfoveal measurement alone and the sample homogeneity.

\section{Ethical disclosures}

Protection of human and animal subjects. The authors declare that no experiments were performed on humans or animals for this study.

Confidentiality of data. The authors declare that they have followed the protocols of their work center on the publication of patient data.

Right to privacy and informed consent. The authors have obtained the written informed consent of the patients or subjects mentioned in the article. The corresponding author is in possession of this document.

\section{Funding}

No funding was obtained.

\section{Conflict of interest}

There is no conflict of interest of the researchers in this study.

\section{References}

1. Yiu G, Pecen P, Sarin N, Chiu SJ, Farsiu S, Mruthyunjaya P, et al. Characterization of the Choroid-Scleral Junction and Suprachoroidal Layer in Healthy Individuals on Enhanced-Depth Imaging Optical Coherence Tomography. JAMA Ophthalmol. 2014;132(2):174-81.

2. Fujimoto JG. Optical coherence tomography. CR Acad Sci Paris. 2001;2(8):1099-111.

3. Lin P, Mettu PS, Pomerleau DL, Chiu SJ, Maldonado R, Stinnett S, et al. Image inversion spectral-domain optical coherence tomography optimizes choroidal thickness and detail through improved contrast. Invest Ophthalmol Vis Sci. 2012:53(4):1874-82.

4. Spaide R, Koizumi H, Pozonni M. Enhanced Depth Imaging Spectral-Domain Optical Coherence Tomography. Am J Ophthalmol. 2008;146:496-500.

5. Maruko I, lida T, Sugano Y, Ojima A, Ogasawara M. Spaide RF Subfoveal choroidal thickness after treatment of central serous chorioretinopathy. Ophthalmology. 2010;117(9):1792-9.

6. Chung SE, Kang SW, Lee JH, Kim YT. Choroidal thickness in polypoidal choroidal vasculopathy and exudative age-relatedmacular degeneration. Ophthalmology. 2011;118(5):840-5.

7. Jirarattanasopa P, Ooto S, Nakata I, Tsujikawa A, Yamashiro K, Oishi A, et al. Choroidal thickness, vascular hyperpermeability, and complement factor $\mathrm{H}$ in age-relatedmacular degeneration and polypoidal choroidal vasculopathy. Invest Ophthalmol Vis Sci. 2012;53(7):3663-72.

8. Nakayama M, Keino H, Okada AA, Watanabe T, Taki W, Inoue M, et al. Enhanced depth imaging optical coherence tomography of the choroid in Vogt-Koyanagi-Harada disease. Retina. 2012;32(10):2061-9.

9. Maruko I, lida T, Sugano Y, Oyamada H, Sekiryu T, Fujiwara T, et al. Subfoveal choroidal thickness after treatment of Vogt-Koyanagi-Harada disease. Retina. 2011;31(3):510-7.

10. Da Silva FT, Sakata VM, Nakashima A, Hirata CE, Olivalves E, Takahashi WY, et al. Enhanced depth imaging optical coherence tomography in long-standing Vogt-Koyanagi Harada disease. Br J Ophthalmol. 2013;97(1):70-4.

11. Switzer DW Jr, Mendonça LS, Saito M, Zweifel SA, Spaide RF. Segregation of ophthalmoscopic characteristics according to choroidal thickness in patients with early age-related macular degeneration. Retina. 2012;32(7):1265-71

12. Manjunath V, Goren J, Fujimoto JG, Duker JS. Analysis of choroidal thickness in age-related macular degeneration using spectral-domain optical coherence tomography. Am J Ophthalmol. 2011;152(4):663-8.

13. Branchini L, Regatieri C, Adhi M, Flores-Moreno I, Manjunath V, Fujimoto JG, et al. Effect of intravitreous anti-vascular endothelial growth factor 
therapy on choroidal thickness in neovascular age-related macular degeneration using spectral-domain optical coherence tomography. JAMA Ophthalmol. 2013;131(5): 693-4.

14. Kim JH, Kang SW, Kim JR, Kim SJ. Variability of subfoveal choroidal thicknessmeasurements in patients with age-related macular degeneration and central serous chorioretinopathy. Eye (Lond). 2013;27(7) 809-15.

15. Hara K. Effects of cigarette smoking on ocular circulation chronic effect on choroidal circulation. Nippon Ganka Gakkai Zasshi. 1991;95: 939-43.

16. Wimpissinger B, Resch $\mathrm{H}$, Berisha F, Weigert G, Schmetterer L, Polak K Response of choroidal blood flow to carbogen breathing in smokers and non-smokers. Br J Ophthalmol. 2004;88(6):776-81.

17. Sizmaz S, Küçükerdönmez C, Pinarci EY, Karalezli A, Canan H, Yilmaz $\mathrm{G}$. The effect of smoking on choroidal thickness measured by optical coherence tomography. Br J Ophthalmol. 2013;97:601-4.
18. Ulas F, Celik F, Do囚an Ü, Celebi S. Effect of Smoking on Choroidal Thickness in Healthy Smokers. Current Eye Res. 2014:39(5):504-11.

19. Sánchez Ramos JA, Espinosa Soto IC, Ramírez-Estudillo JA. Análisis del grosor coroideo en personas fumadoras obtenido mediante Swept Source-OCT. Rev Mex Oftalmol. 2017;91(6):306-10.

20. Moschos MM, Nitoda E, Laios K, Ladas DS, Chatziralli IP. The Impact of Chronic Tobacco Smoking on Retinal and Choroidal Thickness in Greek Population. Oxidative Medicine and Cellular Longevity.2016;1-7.

21. Tayyab H, Jahangir S, Kishi S. Effect of Chronic Smoking on Choroidal Thickness as Measured by Swept Source OCT When Compared to Non Smokers. Pak J Ophthalmol. 2015;31(4):177-81.

22. Benowitz N, Hukkanen J, Jacob P III. Nicotine Chemistry, Metabolism, Kinetics and Biomarkers. Handb Exp Pharmacol. 2009;(192):29-60.

23. Zengin $\mathrm{MO}$, Cinar $\mathrm{E}$, Kucukerdonmez $\mathrm{C}$. The effect of nicotine on choroidal thickness. Br J Ophthalmol. 2014:98:233-7. 